\title{
DR. ARNALDO VIEIRA DE CARVALHO
}

\author{
(dà lição inangural de Clinica Gynecologica)
}

\author{
do Prof. Dr. Nicolau de Moraes Barros
}

Ha cerca de 20 annos, transpunha eu pela primeira vez ás portas da Santa Casa e percorria as suas arcadas a passos curiosos e incertos. Insensivelmente e como que obdecendo, sem me aperceber, a forças obscuras e irresistiveis eu ia ter á primeira enfermaria de cirurgia - mulheres-e alli defirontava um attrahente e singular personagem. Nobre no porte, algo brusco nos gestos, insinuante nas maneiras, tinha I $\mathrm{m}$ olhar de rara agudeza, o riso franco, metallico e communicativo. o Dr. Vieira de Carvalho, de quem se tratava e que então conheci, tra o chefe da enfermaria e o director clinico do hospital. Acolheu-me com a affabilidade e singeleza que lhe eram costumeiras, franqueou-me os seus serviços e conduziu-me em seguida á sala de operações onde nomentos depois praticou uma delicada intervenção de cirurgia abdorninal com pericia pouco vulgar e como eu nâo vira maior nem mais acabada por nenhum dos consumados veteranos da cirurgia européa. Guardo, desse primeiro encontro, impressão que nunca se me apagou.

Já delle então se dizia que era um forte, um espirito talhado para a organisação e para o commando. homem de iniciativas e de realisações, scientista de largos recursos, cirurgiâo eximio. $\mathrm{E}$ não peccava tal juizo por excesso ou benevolencia; na sua pessoa se reuniam, de facto, em conjuncto harmonico e bem equilibrado, todos esses talentos e virtudes que, apurados no cadinho do tempo e com uma experiencia progressivamente maior das coisas e dos homens, trahem o segredo do sei successo e explicam o fulgor pouco commum da trajectoria por elle percorrida.

Nos delineamentos do seu perfil destacam-se traços de relevo pouco vulgar. A sua exalçada aptidão para organisar e dirigir, melhorando e progredindo, era uma das feições mais empolgantes da sua personalidade. Que o diga em linguagem mais suggestiva do que a minha, na muda eloquencia de suas severas linhas architetonicas, esse monumento de bondade e altruismo que é o Hospital Central da Santa Casa.

Vai para trinta annos que ahi começou a se fazer sentir a acção benefica de Vieira de Carvalho. Indagai, senhores, do que era a Santa Casa por esse tempo, com as suas enfermarias, consoante as idéas em curso, mal installadas e mial providas, com os seus arremedos de salas cirurgicas antiquadas na construcção, pobres no material, divorciados dos sãos principios, com as suas restantes dependencias insufficientes ou inadequadas, em que os preceitos scientificos esbarravam a cada passo com tropeços de toda a ordem, onde só era possivel uma caridade manca e dominavam soberanos o atrazo e a rotina. Confrontai-a com 
as installações de hoje, cuja sumptuosidade mede parelhas com a rigorosa applicação dos mais modernos ensinamentos, em que o conforto se casa com a esthetica, com as suas magnificas salas de operações satisfazendo ás menores exigencias, com os seus amplos laboratorios preenchendo cabalmente seus utilissimos fins e não conseguireis dissimular a vossa admiração pela metamorphose realizada, o vosso respeito e o vosso enthusiasmo pela mão forte, pela energia mascula que presidiu a essa transformação. Se nes enfermarias ainda é objectavel o accumulo de doentes em manifesta desproporção com a cubagem das salas, si é gritante o contraste da sua superlotação com as exigencias da moderna hygiene hospitalar, si é condemnavel a promiscuidade em que se mantêm operados limpos, asepticos e casos suppurados, é porque, nestes detalhes, a acção de Vieira de Carvalho soffreu o entrave de circumstancias irremoviveis que zombaram do seu esforço, porisso que o mal apresentava raizes inaccessiveis á mais violenta therapeutica. Sabe Deus quando será possivel extirpal-as! Nem porisso constitue menos essa casa um attestado imperecivel da operosidade tenaz, da actuação bem orientada e do espirito progressista do seu pranteado director.

E' de hontem a sua ausencia! Sob aquellas arcadas ainda se ouvem os seus passos, ainda resôa a sua voz, ainda se obedece ao seu commando. Por todos os recantos paira a sua sombra relembrando os seus feitos, estimulando ao trabalho, despertando zelo pela sua obra. Que não pereça em novas mãos, a preciosa herança. Si não nos fôr dado engrandecel-a, saibamos, ao menos, preserval-a.

o director clinico da Santa Casa tinha de ser o organisador da Faculdade de Medicina. Si assim o aconselhavam o bom senso e a clarividencia administrativos, assim tambem o exigia a logica dos factos, o appello premente das circumstancias. Foi no seio da Santa Casa que germinou, cresceu e amadureceu a idéa da fundação da Facúldade, foi a existencia daquella com os seus amplos recursos, com o sell ambiente scientifico e a sua abundante seiva vivificante que tornou viavel o advento desta. Sem uma, não se cogitaria de outra. Era, pois, de se prever sem medo de incidir em erro, que a Santa Casa se desvelasse pela Faculdade com os mesmos anceios e carinhos com que a mãi extremosa se desvela pela sua criatura que é o fructo de suas entranhas e o sangue do seu sangue, que lhe amparasse o crescimento e a expansão com a mesina solicitude com que lhe amparou os primeiros passos, que lhe prestasse mão forte e decidida para vel-a progredir, brilhar e cobrir-se de louros que seriam tambem seus, que a encheriam de justo orgulho, que avultariam a sua benemerencia. Eis, Srs., a primeira credencial que impunha com a força dos factos inevitaveis, que a Vieira de Carvalho fosse commettida a ingente tarefa.

De resto quem, por sua situação profissional e social, por seu prestigio, pelo conhecimento dos homens e do meio, pela ascendencia exercida sobre a sua classe empunharia com mais autoridade o bastão de chefe e proveria com mais efficiencia ás necessidades do ensino medico?

Quem, com armadura comparavel á sua para afrontar difficuldades, vencer resistencias, desviar tropeços, conter descontentamentos, sopitar desillusōes, suppcrtar, emfim, as mil contrariedades inherentes á afanosa empreitada que lhe atiraram aos hombros?

Ainda novel, em periodo de crescimento, que apenas se abeira da adolescencia, mal accommodada em installações provisorias e improprias, dispersas por varios predios de aluguel, vetustos uns, em ruinas 
cutros, inadaptaveis quasi todos, a nossa Faculdade já conseguio, entretanto, em menos de dous lustros, impôr-se ao apreço e ao respeito da opiniāo como uma officina de trabalho honesto e esforçado, como um centro de estudos sérios onde se ministra ensino util e pratico, como uma retorta fecunda onde se elaboram bons medicos e bons cidadãos. A despeito dos seus andrajos, consoante ás premuras de uma situação financeira desfavoravel, que - praza aos céos não se eternize - contrafeita embora, sem liberdade para se mover e se expandir, já usufrue esta Escola de alentadoras sympathias, já logrou fama que ecôa para muito alêm de nossas fronteiras, já o publico della se occupa com os enlevos e caricias com que se amima um filho dilecto, em cujas manifestações precoces de intelligencia e de caracter se depositam as melhores esperanças.

Se quizerdes uma demonstração a mais, pequenina, mas significativa, da popularidade e do alto apreço de que goza esta Faculdade, ahi tendes o recente concurso de gynecologia, realizado sob o olhar curioso e interessado de todo o mundo leigo, cujas phases e prripecias empolgaram litteralmente a opinião, trazendo-a durante longos dias sus-

nsa e offegante, a commentar provas, discutir diagnosticos, confrontar technicas, aferir preparo e prevêr julgamentos.

E' certo que estava em jogo a subsitituição de um mestre querido e illustre, que se cuidava de preencher um grande claro aberto nas fileiras do magisterio por um golpe inesperado do destino, que, por isso, hcnra excepcional resultaria a quem lograsse conquistar a successão e isso explica em parte o alvoroço do publicò; mas não é menos certo que esse alvoroçado interesse tambem documenta o elevado conceito em que se tem esta casa de ensino, o justo prestigio de que goza o seu corpo de professcres, a confiança que inspiram os seus julgados.

Por situação tão solida e tão promissora cabe a Vieira de Carvalho, de justiça e de direito, o merito e a responsabilidade. Foi elle quem amanhou e semeou a terra, quem se desdobrou em amor e cuidados lara que o fragil broto vicejasse an abrigo da intemperie e a sua tenra folhagem não crestasse ao sol e ao vento, quem se consumio em vigilias exhaustivas para que o arbusto se fizesse arvore, tomasse corpo e adensasse a fronde.

Hoje, que a planta se ostenta em plena exuberancia de viço e robustez, que a galharia se dispersa e se entrelaça e já faz sombra, que se annunciam as primicias dos fructos, não regateemos o nosso applauso ao esforçado cultivador, rendamos-lhe em palmas de admiração e reconhecimento a homenagem de que se fez credor.

Como cirurgião, Vieira de Carvalho realizou este milagre - facto inédito na historia da cirurgia nacional - fez-se á custa propria, dentro dos acanhados recursos do seu meio, sem arredar pé do seu paiz. Até então não havia nesta terra exemplo de uma nomeada cirurgica acima do vulgar, em quem, durante prolongado estagio, não se tivesse abeberado das lições e dos ensinamentos praticos junto aos grandes mestres do Velho Mundo, não se concebia solida reputação technica sem a credencial de pelo menos uma viagem ao extrangeiro. Foi elle o primeiro que discrepou dessa regra, desfez o presupposto e provou a Inanidade do conceito.

Abrindo em S. Paulo a sua tenda de trabalho, aqui meditou sobre as doenças que affligem a humanidade, aqui se dedicou a cural-as ou allivial-as, cultivou o seu espirito, adquirio experiencia, adextrou as mãos. E com tal arte se conduzio e com tal successo, que se fez primus 
inter pares. que cercou o seu nome de aureola refulgente, que o chamaram amiude em escriptos e discursos, o principe dos cirurgióes!

Era um gosto vel-o operar. Gozava-se do mais puro prazer scientifico - intellectual assistindo a uma de suas laparotomias diariamente praticadas na Santa Casa e a que affluiam collegas de toda a parte. Operando, Vieira de Carvalho era a um tempo elegante e meticuloso, ousado e expeditc, calmo e seguro. Da incisão inicial á applicação do ultimo ponto obedecia á mesma technica uniforme e impeccavel, agia com inalteravel firmeza e decisão, mantinha igual sobriedade nos gestos e attitudes. Nas situações mais criticas, a braços com accidentes inesperados e, por vezes embaraçosos, não se enleava nem perdia o prumo, não se lhe perturbava o dominio sobre si e o bom humor. Si acontecia afrouxar uma ligadura ou escapar uma pinça e o sangue, jorrando aos borbotões, inundava o campo e affligia a assistencia, era fatal e indefectivel a piada jocosa, o gracejo esfusiante e opportuno com que transmutava a scena, tranquillizando os espiritos e restal:elcendo a confiança com a mesma rapidez e maestria com que estancava o sangue e dominava a hemorragia. Concluida a tarefa, por vezes afanosa e extenuante, era de ver-se com que bonhomia e despreoccupação elle alludia aos contratempos, si é que alludia e dispunha-se, sem mais delongas, a nova empreitada que o aguardasse.

Era um trabalhador admiravel. Praticava seguidamente e de um só arranco tres e quatro intervenções de alta cirurgia, com o mesmo entrain, na mesma toada, sem que uma palavra ou gesto trahisse a fadiga, que porventura the invadira o corpo ou the affrouxara as mãos. Cançava-se a assistencia de aśsistir, não se cançava o operador de operar.

E' que Vieira de Carvalho realizou, durante largo periodo de sua vida, o pensamento de Haward Kelly - a primeira condição para sir bom cirurgiño é ter boa saude. Só ao homem sadio de corpo e de espirito é dado arcar com o pesado fardo de uma intensa actividade cirurgica, satisfazer ás exigencias permanentes que ella impõe á sua organização physica, attender ás multiplas solicitações com que ella, a cada passo, põe á prova a sua intelligencia, os seus nervos, a sua experiencia, a sua aptidão para julgar e agir.

Cirurgião e opẹador não são expressões que se equivalham, nem vocabulos que se confundam, porque ser cirurgião é muito mais dis que -ser operador. Já muito antes de Kelly, o autorizado especialista đe Baltimore, insistia o grande Billroth por essa distincção affirmando - ruanto é simples e facil a tarefa do operador é difficil e complexa c do cirurgião. Com alguma leitura, um pouco de gosto pelo offficio e abundante material á disposição, a qualquer é licito fazer-se operador, adquirir dextreza technica, lograr successos retumbantes, impressionar a multidão. Confiado na pericia com que corta, liga e sutura, no rigor com que se desinfecta e pratica a asepsia, o operador tem o prurido irresistivel de operar, a solução cirurgica é a primeira, sinão a unica que lhe occorre e de que difficilmente se abstem, o bisturi é como que a varinha magica em que se concentra todo seu poder e todas as suas virtudes. Arranque-se-lh'a das mãos e é corno si se tivesse cortado os cabellos a Sansão. Elle guarda, dos alfarrabios compulsados ha tempos e de relance, que Lawson Tait introduzio em cirurgia a cperação da salpingo-ovarite, que praticou em larga escala e com que se cobrio de glorias e quer, por sua vez, deslumbrar os contemporaneos operando systematicamente quanta salpingo-ovarite lhe vem ás mãos. Porque não tem o habito do estudo meditado e da observação 
com os sentidos e com o raclocinio, elle não assimila e não evolue, náo sabe distinguir as metroragias ovarianas das de causa uterina $\theta$ raspa impiedosamente quanto utero hemorragico se lhe apresente. Não o favoreça o exito e lá vem segunda e terceira raspadela, tão innocuas quanto a primeira e precedidas do aviso, com que aplaina difficuldades futuras, de ser preciso, talvez, recorrer a providencia radical - a hysterectomia salvadora e soberana. Chega a vez desta e a pobre victima perde o seu utero! Pratícou-se uma mutilação insensata e criminosa? ferio-se preceito basico de ethica cirurgica? sacrificou-se a mais nobre das funções organicas? desfez-se a felicidade de um lar? Pouco importa, pois que se curou uma hemorragia rebeldissima, preservou-se uma vida, fez-se jús á gratidão da doente!

Fis. senhores, um typo vulgar dentre os chamados operadores, um e:emplar acabado de ignorancia e improbidade, desses que viçam por toda a parte, verdadeiros flagellos sociaes que escapam á sanç̧ão das leis e usufruem rendosa clinica.

o cirurgião é um pouco mais e melhor do que isso. Para se revestir de suas insignias fazem-se precisas roupagens de mais fina confecção, armadura mais resistente, credenciaes de indiscutivel nobreza e fidalguia. E' cirurgião quem num estudo aprofundado das molestias perscrutou-lhes a natureza e as causas, aprendeu-lhes as modalidades, a evolução e os perigos, apparelhou-se das melhores armas para lhes lar combate; quem numa intima e diaria convivencia com os doentes e com as doenças, acostumou-se a observal-os de perto, apurou os senticlos, ganhou experiencia em ordem, a enxergar com descortino, a interpretar com logica, decidir com presteza e acerto. E' de cirurgião, em cada caso concreto, colher a anamnese com minucia, examinar com methodo, analysar com reflexão para o effeito de precisar a formula diagnostica num exacto criterio clinico e fundar a indicação therapeutica numa justa e ponderada apreciação das circumstancias. Adoptada a solução operatoria, é ainda de cirurgião inspirar-se nos ensinamentos da experiencia e nas razões scientificas, para julgar da ( pportunidare da intervenção. das condições em que cumpre pratical-a, do processo operatorio a ser preferido. $E^{\prime}$ cirurgião, finalmente, aquelle que num respeito fetichista pela vida que lhe é confiada, esquecido de sua pessoa e norteado pela preoccupação obsedante do 'non nocere', sabe resistir ás seducções de um exito facil e brilhante para se abster de operações que a sua pratica e a sua consciencia lhe dizem contra indicadas ou adiaveis, para só operar quando e como o exize o mais rigoroso determinismo scientifico.

Feito o cortejo e esboçado o quadro não será preciso indicar-vos a moldura que a elle se ajusta, pois o vosso atilamento e espirito critico já sentenciaram ccm justiça e sabedoria: Vieira de Carvalho era cirurgião. Não me cabe dizer-vos em que proporção nelle se juntavam entrelaçados e solidarios todos aquelles predicados que formam a essencia do bom cirurgião. E' possivel que na sua formação artistica discrepasse um ou outro detalhe, que sob determinados pontos de vista, se ihe notassem desigualdades e falhas, mas que, em todo o caso, careciam de valor para affectar o inteiriço da peça ou comprometter a harmonia do conjuncto. Nas linhas mais accentuadas do seu perfil se reconheciam sem esforço os traços caracteristicos de uma sadla organisação cirurgica.

E no dominio da cirurgia foram as molestias genitaes da mulher o campo predilecto da sua actividade, onde se sentia mais a vontade.

Com anthusiasmo que nunca arrefeceu, Vieira de Carvalho, ao mesmo 
passo que dava expansão ao seu temperamento e obedecia ás tendencias do seu espirito, imprimia um cunho todo pessoal, inteiramente seu ao modo de encarar os assumptos, de solucionar as questões, de se conduzir em cada caso. Operando muito, praticando laparotomias diarias, mercê do rico material que lhe proporcionavam o hospital e a clientela, elle logrou, ao cabo de algum tempo, technica tão exacta, mãos tão ageis e seguras, que difficilmente alguem o excederia na precisão e rapidez de suas operações.

Se ha exagero em affirmar que Vieira de Carvalho foi o creador da synecologia operatoria entre nós, é incontestavel que elle foi aqui o vulgarisador das grandes intervenções gynecologicas. Datam da sua época e promanam da sua actividade a inclusão no ról das operações correntes e accessiveis á maioria dos nossos cirurgiões, das hysterectomias abdominaes e vaginaes, das ovariotomias e das diversas pexias utero-ligamentares. As suas demonstrações praticas feitas todos os dias e durante annos nas salas cirurgicas da Santa Casa, constituiram um verdadeiro curso da especialidadẻ, precursor do que elle mais tarde com tanta proficiencia, iniciava como cathedratico da Faculdade. Se hoje em S. Faulo a cirurgia abdominal é tão larga e tão brilhantemente praticada, valendo aos nossos profissionaes nomeada tão bella e á nossa profissão prestigio tão alto deve-se em parte apreciavel e sem nenhum favor, á escola de Vieira de Carvalho. Elle se fez o primeiro dos nossos gynecologistas, a mais acatada autoridade em assumptos dessa disciplina medica. Era, portanto, natural, como era logico e jnevitavel, a sua investidura na catliedra de gynecologia da Faculdade de Medicina.

Nessa derradeira phase de sua vida não me foi dado acompanha-1o tão de perto quanto eu desejara, nem tive a fortuna de ouvir uma só de suas lições. Quem leu, entretanto, a sua prelecção inaugural não precisou de mais para aferir do seu preparo scientifico, da sua cultura, dc seu espirito philosophico, de suas invejaveis qualidades didacticas.

Vivendo sob o mesmo céo, respirando o mesmo ar, mourejando na mesma labuta, conheci bem as seducções da sua pessoa, testemunhei o respeito e o filial affecto de que o cercavam os seus discipulos, partilhei da dor que alanceou os corações, quando o vento da morte, numa rajada brutal e traiçoeira o arrebatou.

Tal foi, senhores, em eshoço desalinhado e incolor a singular figura de homem e de scientista a quem o destino me faz succeder. Successão difficil e honrosa, disse eu algures e repito hoje! Encargo de grande peso e responsabilidade para quem ensaia as suas primeiras armas no magisterio e só conta com o proprio esforço para vencer. Pouco importa! 'Tenho o habito do trabalho e o espirito affeito ás lutas. Não vos fálte boa vontade, que a mim não me faltará animo rem decisão. Trabalhemos, pois, com afinco e desassombro, viseira erguida e olhos fitos no futuro. Se acontecer em meio da jornada nos escasseareni as energias e nos entorpecerem os membros, retemperemol-os á lembrança do mestre desapparecido, busquemos novo alento no exemplo que elle deixou. Se, ainda assim, não nos protegerem of fados nem nos permittir o destino vencer os tropeços do caminho e alcançar o termo da viagem, que, ao menos "nos seja dado attingir a curva da estrada e galgar o outeiro donde se possa divisar distante, i:a bruina longinque, a linha jugltva do horizonte onde repousam is nossos ideaes'. 
